\title{
SUBCUTANEOUS ADMINISTRATION OF INFLIXIMAB-ATTENUATED SILICA-INDUCED LUNG FIBROSIS
}

\author{
HUA ZHANG ${ }^{1,2}$, JUN-NA SUI ${ }^{3}$, LEI GAO ${ }^{4}$, and JIAN GUO ${ }^{3}$ \\ ${ }^{1}$ Qilu Hospital of Shandong University, Jinan, China \\ Department of Respiratory Medicine \\ ${ }^{2}$ Qingdao Central Hospital, Qingdao, China \\ Department of Occupational Disease \\ ${ }^{3}$ Qingdao Central Hospital, Qingdao, China \\ Department of Clinical Laboratory \\ ${ }^{4}$ Qingdao Blood Center, Qingdao, China \\ Department of Clinical Laboratory
}

\begin{abstract}
Objectives: To investigate the influence of the anti-tumor necrosis factor- $\alpha$ infliximab (IFX) in the case of rats with silicosis. Material and Methods: Forty-eight Wistar rats were randomly divided into 3 groups. The study group $(\mathrm{N}=16)$ - silicosis was induced by intratracheal instillation of $50 \mathrm{mg}$ silica on day 1, and IFX was subcutaneously administered at a dose of $15 \mathrm{mg} / \mathrm{kg}$ of body weight from day 2 to day 6 , the vehicle group $(\mathrm{N}=16)$ - silica used as the study group but without IFX, the sham group $(\mathrm{N}=16)-1 \mathrm{ml}$ of saline was intratracheal-used. Eight rats in each group were euthanized on day 7 and on day 14, respectively. Lung tissue sections were stained with hematoxylin and eosin or Masson's trichromedye. The nuclear factor- $x \mathrm{~B}$ p65 (NF- $x \mathrm{~B}$ p65) positioning in the lung tissues were determined by immunohistochemical staining. Levels of tumor necrosis factor $\alpha$ (TNF- $\alpha$ ) in rat serum and bronchoalveolar lavage fluid were measured with enzyme linked immunosorbent assay. The inducible nitric oxide synthase (iNOS) mRNA in the lung tissues was measured by quantitative real-time polymerase chain reaction, as well as inhibitor protein- $\varkappa \mathrm{B}(\mathrm{I}-\varkappa \mathrm{B})$ and $\mathrm{NF}-\varkappa \mathrm{B}$ p65 expression were measured quantitatively by western blotting. Results: Silica installation increased the lung tissues inflammation reaction, oxidative stress and pulmonary fibrosis. Infliximab treatment significantly improved silica-induced lung pathological changes (inflammatory cells, collagen deposition), decreased the TNF- $\alpha$ inhibited NF- $\varkappa$ B signaling (I- $\varkappa \mathrm{B}, \mathrm{NF}-\varkappa \mathrm{B}$ p65) as well as oxidant status (iNOS). Conclusions: Infliximab may improve silica-induced pulmonary inflammation by decreasing the TNF- $\alpha$, inhibiting NF- $\chi \mathrm{B}$ signaling (I- $\varkappa \mathrm{B}, \mathrm{NF}-\varkappa \mathrm{B}$ p65) as well as oxidant status (iNOS), which suggest that IFX has potential role in the treatment of silica-induced lung damage. Int J Occup Med Environ Health 2018;31(4):503-515
\end{abstract}

Key words:

Infliximab, Silicosis, TNF- $\alpha$, Rat model, NF- $\varkappa$ B, iNOS

Funding: this work was supported by Qingdao Science and Technology Development (project No. KJZD-12-23-nsh entitled "Effects of Tumor Necrosis Factor-alpha in Pathogenesis and Therapy of silica Exposed animal Model," project manager: Hua Zhang, Ph.D.).

Received: June 12, 2016. Accepted: September 25, 2017.

Corresponding author: Jian Guo, Qingdao Central Hospital, Department of Clinical Laboratory, 127 Siliu Nan Road, Qingdao 260042, China (e-mail: Wudaojguo2015@126.com). 


\section{INTRODUCTION}

Silicosis caused by inhalation of crystalline silica is an irreversible potentially fatal lung pneumoconiosis, characterized by inflammation and fibrosis of the lung [1,2]. Despite significant progress in its research, the exact mechanism of silicosis has not yet been elicited. Silicosis is believed to be initiated by an increased number of activated alveolar macrophages, releasing numerous inflammatory mediators, which play crucial roles in the occurrence and development of the disease [3]. Despite extensive effort, no significant effective treatment method is available to reverse or slow the disease process [4-6]. Novel approaches for key cytokines targeted at treatment of silica-induced inflammation and fibrosis are urgently needed.

Tumor necrosis factor $\alpha$ (TNF- $\alpha)$ as an activator, plays a key role in the inflammatory and fibrogenic responses of silicosis [7]. Exogenous recombinant TNF- $\alpha$ augments silicotic fibrosis and anti-TNF antibody attenuates silicosis, and silicosis are absent in TNF- $\alpha$ receptor knockout mice [8-10]. Tumor necrosis factor $\alpha$ in a canonical manner triggers nuclear factor- $x \mathrm{~B}(\mathrm{NF}-\boldsymbol{x} \mathrm{B})$ activation which may occur in several pathways [11-13]. Nuclear factor- $x \mathrm{~B}$ as a transcription factor plays a fundamental role in the pathogenesis of silicosis. Binding of NF- $\varkappa \mathrm{B}$ to DNA promotes up-regulation of inducible genes involved in mediating the inflammatory and fibrotic responses to silica [14-16]. Tumor necrosis factor $\alpha$ also activates inducible nitric oxide synthase (iNOS) to produce nitric oxide (NO) in respiratory epithelium [17]. As a reactive nitrogen species, iNOS-derived NO contributes to the pathogenesis of silica-induced lung disease, up-regulating inflammatory cytokines and amplifies the inflammatory response [18,19].

Infliximab (IFX) is a chimeric monoclonal immunoglobulin G1, neutralizing TNF- $\alpha$ biologic activity with a high affinity and specificity to human membrane-bound and soluble TNF- $\alpha$ [20-22]. Infliximab has demonstrated a protective effect on acute lung injury induced by intestinal isch- emia/reperfusion, airway smooth muscle hyper-reactivity of asthma and cigarette smoking-induced emphysema by reducing lung inflammation and improving pathological changes [23-26]. It is also effective in attenuating bleomycin-induced (BLC-induced) pulmonary fibrosis and IFX per se does not result in pulmonary fibrosis [27].

Since no more biochemical and histopathological changes on pulmonary fibrosis induced by silicosis in the case of rats by IFX pretreatment had been reported, the aim of this study was to examine the protective effects and mechanism of action of subcutaneously-administered IFX on the silicainduced lung inflammation and fibrosis in the rat model.

\section{MATERIAL AND METHODS}

\section{Dust sampling and suspension preparation}

Silica content of the quartz dust (Sigma-Aldrich, St Louis, MO, USA) was $>99 \%$ and the particle size of the dust was $0.5-10 \mu \mathrm{m}$ with $80 \%$ of the dust particles were $1-5 \mu \mathrm{m}$. Crystalline silica particles were suspended in saline at $50 \mathrm{mg} / \mathrm{ml}$ after sterilization $\left(121.3^{\circ} \mathrm{C}, 103.4 \mathrm{kPa}\right.$ for $\left.90 \mathrm{~min}\right)$, and then added with penicillium to make the final concentration of $8000 \mathrm{U} / \mathrm{ml}$ in silicon suspension [28].

\section{Animals and experimental design}

Male Wistar rats (6-8-week old, 180-220 g in weight) were obtained from the Food and Drug Administration, Qingdao, China and kept on an alternating $12 \mathrm{~h}$ light $/ 12 \mathrm{~h}$ dark cycle under standard temperature $\left(22 \pm 2^{\circ} \mathrm{C}\right)$ and humidity $(60 \pm 5 \%)$. The rats were acclimatized for 7 days before the start of the experiment with standard chew food and water freely available. The animal experimental protocol complied with the Animal Management Rules of the Chinese Ministry of Health (document No. 55, 2001) and was approved by the Animal Care Committee, Qingdao Food and Drug Administration.

Forty-eight rats were randomly divided into 3 experimental groups according to their experimental treatment as follows: the treatment group $(\mathrm{N}=16)$, the vehicle group $(\mathrm{N}=16)$ 
and the sham group $(\mathrm{N}=16)$. The vehicle group was anesthetized with $40 \mathrm{mg} / \mathrm{kg}$ pentobarbital sodium via intraperitoneal injection and received a single trans-oral (TO) intratracheal instillation of silica suspension of $1 \mathrm{ml}$ as described previously [29]. The sham group received the same procedure but received an equal volume of saline instead of silica. The treatment group received a single dose of $15 \mathrm{mg} / \mathrm{kg}$ IFX (Remicade, Cilag AG Pharmaceutical Company, Switzerland, registration certificate No. for the imported drug: s20120012) dissolved in $0.2 \mathrm{ml}$ of a diluent consisting of normal saline subcutaneously on day 2 to 6 for 5 days overall after silica installation as described previously [30]. Animals were sacrificed using sodium pentobarbital ( $120 \mathrm{mg} / \mathrm{rat}$ ) on days 7 or 14 after silica instillation.

\section{Peripheral blood}

\section{and bronchoalveolar lavage fluid (BALF)}

Blood samples were harvested from abdominal aorta. Serum was separated by centrifugation and then stored at $-80^{\circ} \mathrm{C}$ for analyses.

After the blood had been sampled, the right lung was ligated at the bronchi with surgical wire and BALF was collected by washing the left lung with 3 separate aliquots of $2 \mathrm{ml}$ saline at $37^{\circ} \mathrm{C}$ through a tracheal cannula. Bronchoalveolar lavage fluid was centrifuged and stored at $-80^{\circ} \mathrm{C}$.

\section{Pathologic examination}

\section{of lung inflammation and fibrosis}

The intact right lung lobes were removed, blotted dry, the middle lobe was fixed in $10 \%$ formalin and processed for routine histology in paraffin wax. Sections were prepared of $4 \mathrm{~mm}$ in size, stained with hematoxylin and eo$\sin (\mathrm{H} \& \mathrm{E})$ for histopathology and Masson's trichrome for collagen deposition. The lung tissues were examined in random and blind conditions with standard light microscopy. The degree of lung tissue inflammation was evaluated quantitatively by $\mathrm{H} \& \mathrm{E}$ staining according to its severity. A score ranging from 0 to 4 was designed and the average score was calculated for each group [15]. The Masson's trichrome staining method was used for determining the severity of fibrosis and the quantitative grade of pulmonary fibrosis was blindly scored by randomly selecting regions according to the method introduced by Ortiz et al. [16]. A score ranging from 0 to 8 was assigned and the scores were averaged per group.

\section{Immunohistochemical assessment} of nuclear factor- $x \mathrm{~B}$ p65 (NF- $x \mathrm{~B}$ p65) in lung tissue

Lung sections, $4 \mu \mathrm{m}$ thick, were deparaffinized and then soaked in hydrogen peroxide (3\%) for 15 min to inactivate endogenous peroxidase antigens. Antigen retrieval was performed by means of a pressure cooker (ethylene diaminetetraacetic acid, $\mathrm{pH}=9$; for $15 \mathrm{~min}$ at $90^{\circ} \mathrm{C}$ ). Following serum sealing for $30 \mathrm{~min}$, primary antiNF- $x$ B p65 (Proteintech group, Inc., USA) was added and incubated for $1 \mathrm{~h}$ at $37^{\circ} \mathrm{C}$. The slides were washed with phosphate buffered saline (PBS) and then incubated with peroxidase-conjugated anti-rabbit IgG (Proteintech group, Inc., USA) for $0.5 \mathrm{~h}$ at $37^{\circ} \mathrm{C}$. Staining was then performed using a 3,3'-diaminobenzidine staining kit (ZSGBBio Co. Ltd., China). Phosphate buffered saline was used in the negative control group instead of primary antibody. A positive reaction was indicated by brown staining in the nuclei and cytoplasm. The immunohistochemical staining was evaluated under an Olympus light microscope, ImagePro Plus software v. 6.0 (Media Cybernetics, Inc., USA).

\section{Determine TNF- $\alpha$ level in serum and BALF}

Tumor necrosis factor $\alpha$ was measured in BALF and serum using commercial enzyme-linked immunosorbent assay (ELISA) kits (R\&D Systems, USA) used according to the manufacturer's instructions.

\section{Determine iNOS mRNA}

The quantitative analysis of mRNA for iNOS and $\beta$-actin was performed by real-time polymerase chain reaction 
(PCR) using CFX96 real-time PCR detective system (BioRad Laboratories, Inc., USA) and SYBR Green technology. Total RNA was extracted from lungs with the RNAisoPlus Kit (Takara Bio, Inc., Japan) according to the manufacturer's instructions. Ribonucleic acid purity and concentration were determined using a spectrophotometer NanoDrop2000c (Thermo Fisher Scientific Inc., USA). Complementary DNA was synthesized from deoxyribonuclease-treated total RNA $(1 \mu \mathrm{g})$ with the PrimeScript RT reagent kit with gDNA Eraser (Takara Bio, Inc., Japan) and reverse transcription-real-time PCR was performed with the SYBR Premix EX Taq II (Takara Bio, Inc., Japan) according to the manufacturer's protocol.

The primers (SangonBioteck, Co., Ltd, China) had the following sequences:

1. iNOS - forward 5'-ACGGAGAACAGCAGAGTTGG-3' and reverse 5'-TGTTGGGCTGGGAATAGCAC-3';

2. $\beta$-actin - forward 5'-CCCATCTATGAGGGTTAC-3' and reverse 5'-TTTAATGTCACGCACGATTTC-3'.

The following thermocycling conditions were used: initial polymerase activation step for $30 \mathrm{~s}$ at $95^{\circ} \mathrm{C}$, followed by 40 cycles of $5 \mathrm{~s}$ at $95^{\circ} \mathrm{C}$ for template denaturation, $30 \mathrm{~s}$ at $60^{\circ} \mathrm{C}$ for annealing and extension. All samples were amplified by fluorescence measurement in triplicates and the mean was used for quantitative real-time polymerase chain reaction (RT-qPCR) analysis. Relative levels of target mRNA expression were calculated using the $2^{-\Delta \Delta C \mathrm{~T}}$ method and normalized by endogenous control ( $\beta$-actin).

\section{Analysis of NF- $x \mathrm{~B}$ p65 and inhibitor protein- $x \mathrm{~B}(\mathrm{I}-\chi \mathrm{B})$}

Total protein was extracted from lung tissue using protein extraction reagents (Shanghai Solarbio Bioscience \& Technology Company, China), and protein concentrations measured using a BCA protein assay kit (Solarbio, China) according to the manufacturer's instructions. Protein extracts were loaded onto a $12 \%$ sodium dodecyl sulphate- polyacrylamide gel (SDS-polyacrylamide gel) $(40 \mu \mathrm{g} /$ well $)$ and electrophoretically transferred to polyvinylidenedifluoride (PVDF) membranes. After blocking for $3 \mathrm{~h}$ with $5 \%$ skim milk in phosphate buffered saline with tween (PBST) (PBS with $1 \%$ polyoxyethylenesorbitan fatty acid esters) buffer at room temperature, membranes were incubated overnight at $4^{\circ} \mathrm{C}$ with polyclonal rabbit anti-rat NF- $x$ B p65 (1:5000) (Proteintech Group, USA), polyclonal rabbit anti-rat I- $\varkappa$ B (1:1000) (Immunoway Inc., USA) in skim-milk PBST. The PVDF membranes were washed for 3 times with PBST and incubated with peroxidase-conjugated polyclonal goat anti-rabbit secondary antibody (1:5000) (Beijing Biosynthesis Biotechnology Co., Ltd., China) for $1 \mathrm{~h}$ at room temperature.

Following final washes, protein signals were visualized using the enhanced chemiluminescence reagents (Beijing ComWin Biotech Co., Ltd, China) and detected by the fusion imaging system (Vilber Lourmat Company, France). Beta-actin protein was visualized and detected in the same way. The intensity of each signal spot was quantified using the ImageJ 2x software (Wayne Rasband, National Institutes of Health, USA) that was used for semiquantifing mean optical density of NF- $\chi \mathrm{B}$ p65 and $\mathrm{I}-\varkappa \mathrm{B}$ expression.

\section{Statistical analysis}

All data is presented as mean $(\mathrm{M}) \pm$ standard error $(\mathrm{SE})$. The statistical analyses were performed using SPSS 22.0 software (SPSS Inc., USA) and GraphPad Prism 6.0 (GraphPad, USA). Statistical significance was determined by oneway analysis of variance (ANOVA) followed by the post hoc least significant difference test (LSD-t) and $p<0.05$ was considered statistically significant.

\section{RESULTS}

\section{Histopathological findings}

Representative sections of rat lung tissue are shown in the Figure 1. Normal alveolar structure, lack of inflammatory 

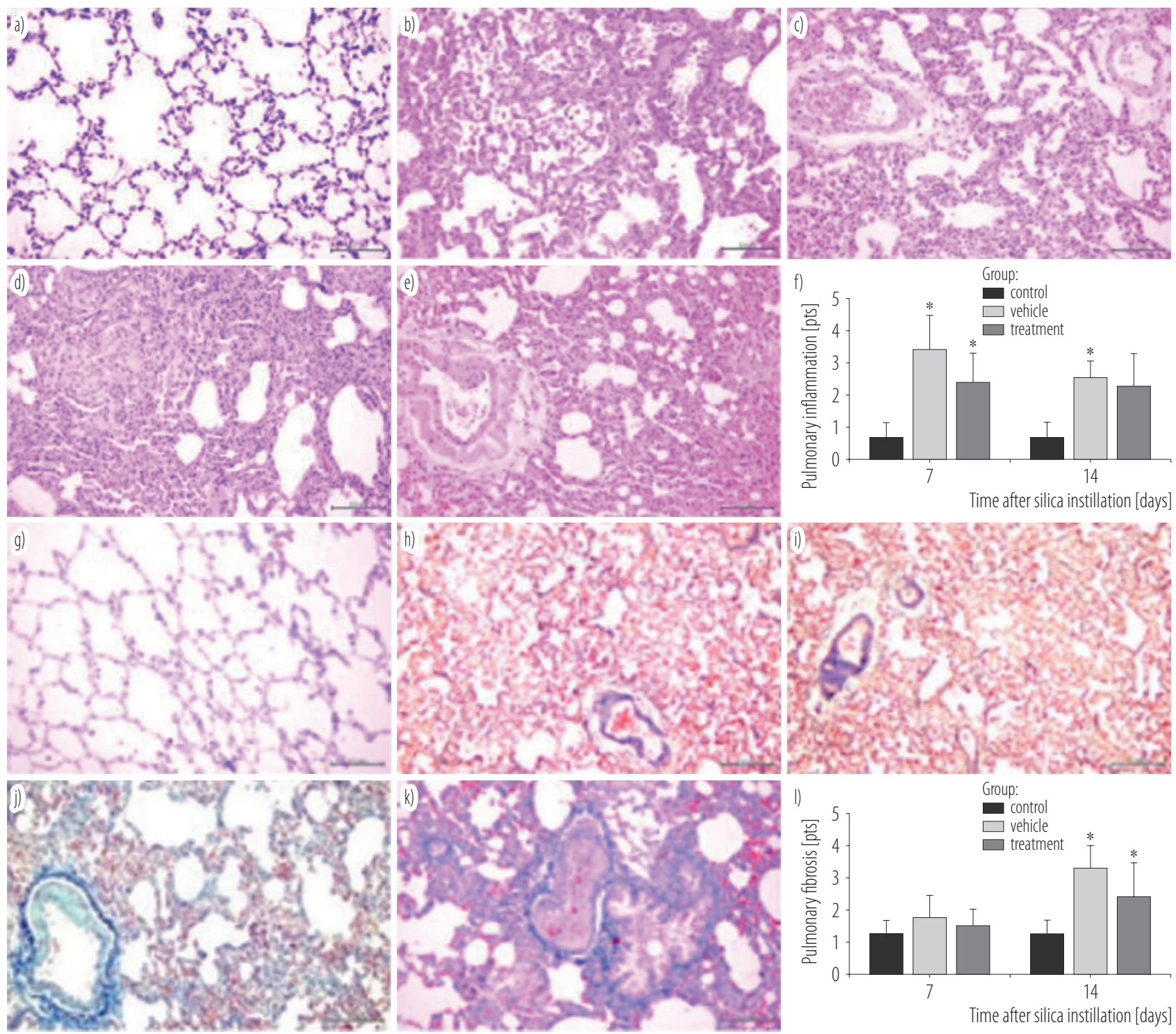

Hematoxylin and eosin (H\&E) staining: a) sham group, day 7; b) vehicle group, day 7; c) treatment group, day 7; d) vehicle group, day 14;

e) treatment group, day 14 .

Pulmonary inflammation and fibrosis score ( 0 - normal lung, 8 - total fibrous obliteration of the microscope field): f) on day 7 after instillation of silica or saline control, 1) on day 14 after instillation of silica or saline control. Data presented as mean \pm standard error.

Masson's trichrome staining: g) sham group, day 7; h) vehicle group, day 7; i) treatment group, day 7; j) vehicle group, day 14; k) treatment group, day 14.

Treatment group $(\mathrm{N}=16)$ - silicosis was induced by intratracheal instillation of $50 \mathrm{mg}$ silica on day 1, and IFX was subcutaneously administered at a dose of $15 \mathrm{mg} / \mathrm{kg}$ of body weight from day 2 to day 6.

Vehicle group $(\mathrm{N}=16)$ - received silica as treatment group but without IFX.

Sham group $(\mathrm{N}=16)$ - received the same procedure as vehicle group but with equal volume of saline instead of silica.

Eight rats in each group were euthanized on day 7 and the next 8 rats on day 14 after silica instillation.

$* \mathrm{p}<0.05$ vehicle group vs. sham group (one-way analysis of variance and least significant difference test).

Fig. 1. Representative sections (4- $\mu$ m thickness) of rat lung tissue stained with H\&E for histopathology and Masson's trichrome for collagen deposition (original magnification $\times 200$ ) 
cellular infiltration and fibrous thickening, was observed in the case of the sham rats (Figure 1a).

On day 7 after instillation, acute inflammation and alveolar wall thickening with infiltration of macrophages, lymphocytes and neutrophils into the alveoli were observed in lung tissue of the vehicle group (Figure 1b). On the contrary, IFX treatment provided protection against silicainduced lung tissue damage with the reduction of alveolitis severity on day 7 (Figure 1c).

On day 14, animals in the untreated vehicle group showed extensive pulmonary lesions including multifocal areas of intense fibrosis with the number of neutrophils decreasing and the number of lymphocytes increasing. What's more, granulomas containing macrophages, neutrophils and fibroblasts apparently increased and enlarged, as compared with day 7 (Figure 1d and 1e). In Masson's trichrome stained sections, the sham group had normal collagen fibers distribution
(Figure 1g). In contrast, the untreated vehicle group showed weak collagen deposition on day 7 (Figure $1 \mathrm{~h}$ and 1i). Increases in collagen deposition began remarkable following instillation on day 14 (Figure 1j). The degree of fibrosis was suppressed in the lungs of the silica-administered rats with IFX treatment (Figure 1k). Inflammation (day 7) and fibrosis (day 14) score were decreased significantly in the IFX-treatment group as compared to the vehicle group $(\mathrm{p}<0.05)$ (Figure 1f and 11).

\section{Immunohistochemical findings}

Sections as shown in the Figure 2a, the sham rats lung tissue section showed a faint degree of immune staining for NF- $\chi B$ p65. Silica exposure significantly increased the NF- $x \mathrm{~B}$ p65 levels of nuclear protein in the lung tissues, which was evident from intense brown staining distributed in nucleus and cytoplasm of alveolar macrophages
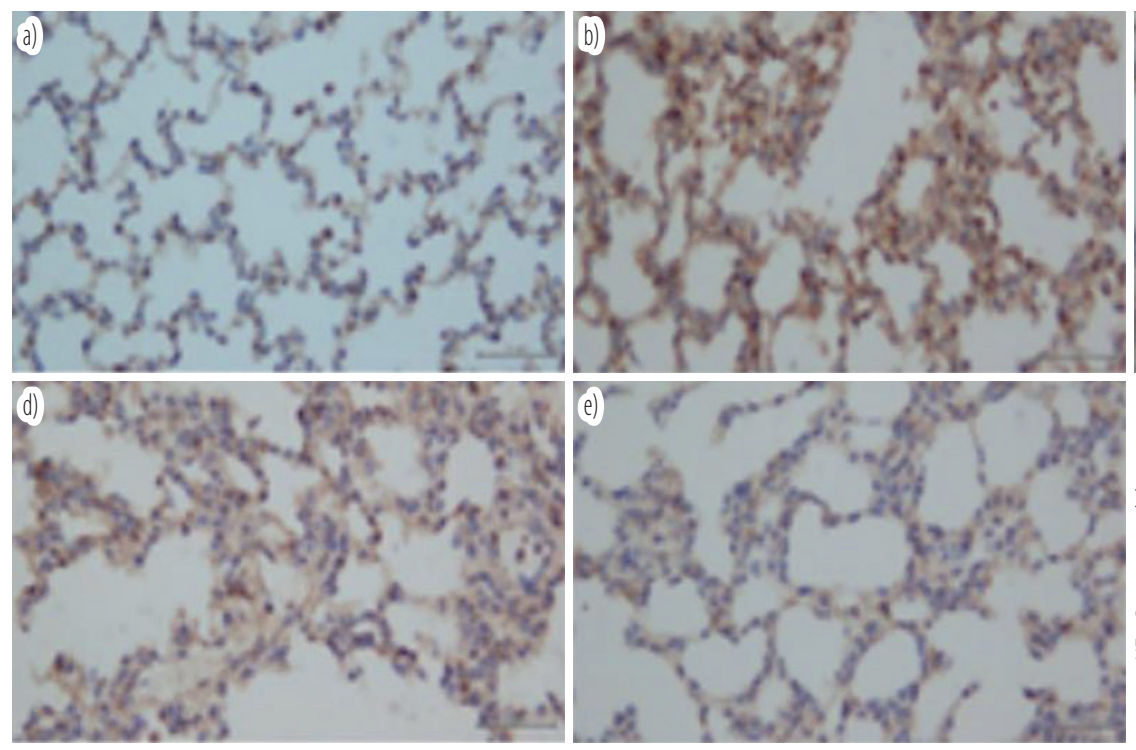
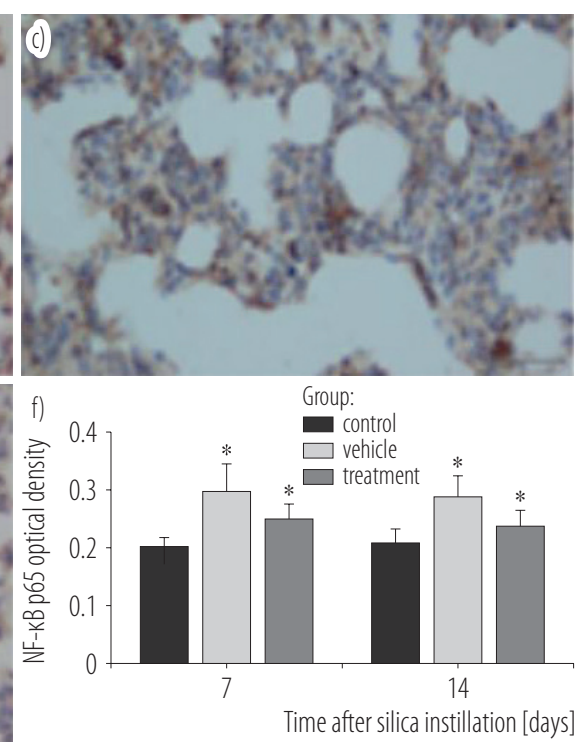

a) section of lung in sham group showing normal architecture, day 7; b) and c) section of lung in vehicle group showing extensive NF- $x$ B p65 expression (brown color) in tissue, day 7 and day 14, respectively; d) and e) in contrast, section of lung in infliximab (IFX) treated group showing limited NF- $\varkappa$ B p65 expression, day 7 and day 14, respectively; f) mean optical density of NF- $\varkappa$ B p65 staining in immunohistochemical sections represents quantification of NF- $x \mathrm{~B}$ p 65 expression (data presented as mean \pm standard error).

$* \mathrm{p}<0.05$, compared with sham/vehicle group (one-way analysis of variance and least significant difference test). Groups as in Figure 1.

Fig. 2. Immunohistochemical analysis of nuclear factor- $x \mathrm{~B}$ p65 (NF- $x \mathrm{~B}$ p65) in rats' lung sections (original magnification $\times 400)$ 
Table 1. Serum and bronchoalveolar lavage fluid (BALF) levels of tumor necrosis factor $\alpha$ (TNF- $\alpha$ ) in rats measured using enzyme-linked immunosorbent assay (ELISA)

\begin{tabular}{|c|c|c|c|c|c|c|}
\hline \multirow{3}{*}{ Sample } & \multicolumn{6}{|c|}{$\begin{array}{c}\text { TNF- } \alpha \text { concentration } \\
{[\mathrm{ng} / \mathrm{l}]} \\
(\mathrm{M} \pm \mathrm{SE})\end{array}$} \\
\hline & \multicolumn{3}{|c|}{ on day 7} & \multicolumn{3}{|c|}{ on day 14} \\
\hline & $\begin{array}{l}\text { sham group } \\
\quad(\mathrm{N}=8)\end{array}$ & $\begin{array}{l}\text { vehicle group } \\
\quad(\mathrm{N}=8)\end{array}$ & $\begin{array}{l}\text { treatment group } \\
\qquad(\mathrm{N}=8)\end{array}$ & $\begin{array}{l}\text { sham group } \\
\qquad(\mathrm{N}=8)\end{array}$ & $\begin{array}{l}\text { vehicle group } \\
\quad(\mathrm{N}=8)\end{array}$ & $\begin{array}{l}\text { treatment group } \\
\quad(\mathrm{N}=8)\end{array}$ \\
\hline Serum & $42.97 \pm 4.38$ & $86.41 \pm 7.25$ & $66.57 \pm 7.02^{*}$ & $45.58 \pm 5.16$ & $77.06 \pm 4.18$ & $58.73 \pm 5.78^{*}$ \\
\hline BALF & $36.46 \pm 4.40$ & $69.46 \pm 8.34$ & $49.13 \pm 6.09^{*}$ & $38.55 \pm 4.57$ & $50.76 \pm 5.86$ & $47.35 \pm 4.59$ \\
\hline
\end{tabular}

$\mathrm{M}$ - mean; SE - standard error.

$* p<0.05$, compared with sham/vehicle group (one-way analysis of variance and least significant difference test).

Groups as in Figure 1.

and epithelial cells (Figure $2 \mathrm{~b}$ and $2 \mathrm{c}$ ). However, treatment with IFX markedly inhibited the expression of NF- $x$ B p65 (Figure $2 d$ and 2e), as compared to the vehicle group (Figure $2 \mathrm{f})(\mathrm{p}<0.05)$.

\section{ELISA to determine cytokine levels}

\section{in serum and BALF}

Serum and BALF levels of TNF- $\alpha$ were shown in the Table 1 . Serum TNF- $\alpha$ level was found considerably higher in the vehicle group than in the sham group at both times.
Infliximab treatment significantly decreased TNF- $\alpha$ level as compared with the vehicle group (Figure $3 a)(p<0.05)$. However, upon IFX treatment, BALF TNF- $\alpha$ level was down-regulated and found only on day 7 ( $p<0.05)$ but not on day 14 (Figure 3b).

\section{Quantitative real-time PCR analysis of iNOS mRNA expression}

Lung tissues-based iNOS gene expression was shown in the Table 2. Inducible nitric oxide synthase mRNA ex-
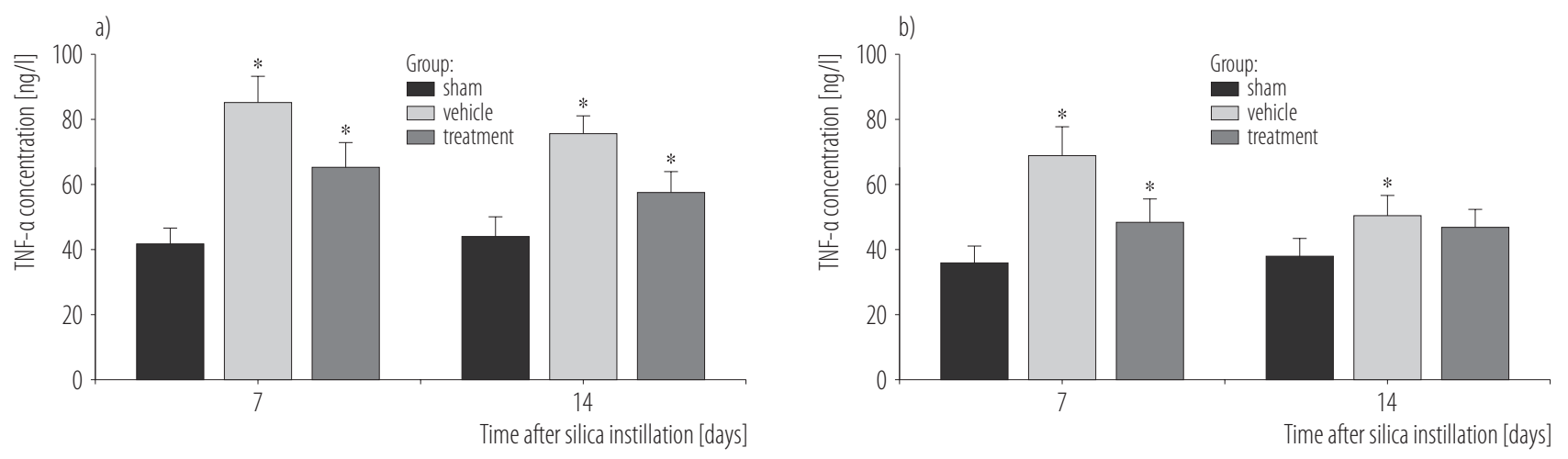

Data presented as mean \pm standard error.

$* p<0.05$, compared with sham/vehicle group (one-way analysis of variance and least significant difference test).

Groups as in Figure 1.

Fig 3. Tumor necrosis factor $\alpha$ (TNF- $\alpha$ ) concentration measured using enzyme linked immunosorbent assay (ELISA) in rats':

a) serum, b) bronchoalveolar lavage fluid (BALF) 
Table 2. Inducible nitric oxide synthase (iNOS) mRNA expression level in lung tissues of rats measured using real-time quantitative polymerase chain reaction (RT-qPCR)

\begin{tabular}{lcccccc}
\hline & \multicolumn{5}{c}{$\begin{array}{c}\text { iNOS mRNA expression level } \\
(\mathrm{M} \pm \mathrm{SE})\end{array}$} \\
\cline { 2 - 7 } Sample & on day 7 & \multicolumn{3}{c}{ on day 14 } \\
\cline { 2 - 7 } & $\begin{array}{c}\text { sham group } \\
(\mathrm{N}=8)\end{array}$ & $\begin{array}{c}\text { vehicle group } \\
(\mathrm{N}=8)\end{array}$ & $\begin{array}{c}\text { treatment group } \\
(\mathrm{N}=8)\end{array}$ & $\begin{array}{c}\text { sham group } \\
(\mathrm{N}=8)\end{array}$ & $\begin{array}{c}\text { vehicle group } \\
(\mathrm{N}=8)\end{array}$ & $\begin{array}{c}\text { treatment group } \\
(\mathrm{N}=8)\end{array}$ \\
\hline Lung tissue & $10.29 \pm 0.19$ & $12.91 \pm 0.21$ & $11.66 \pm 0.14^{*}$ & $10.31 \pm 0.16$ & $12.60 \pm 0.18$ & $12.03 \pm 0.22^{*}$ \\
\hline
\end{tabular}

$\mathrm{M}$ - mean; SE - standard error.

$* p<0.05$, compared with sham/vehicle group (one-way analysis of variance and least significant difference test).

Groups as in Figure 1.

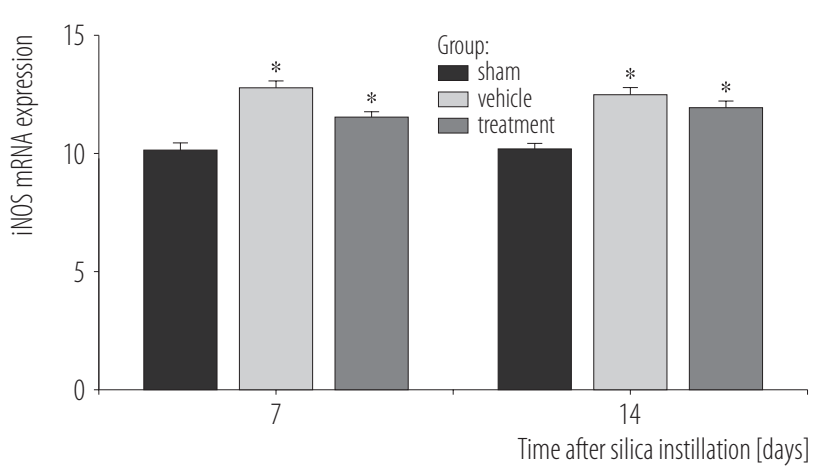

Data presented as mean \pm standard error.

$* \mathrm{p}<0.05$, compared with sham/vehicle group (one-way analysis of variance and least significant difference test).

Groups as in Figure 1.

Fig. 4. Inducible nitric oxide synthase (iNOS) mRNA expression level in lung tissues of rats measured using real-time quantitative polymerase chain reaction (RT-qPCR)

pression level was significantly higher in the vehicle group rats than in the sham group, IFX treatment significantly reduced iNOS mRNA expression on day 7 and 14 as compared to the vehicle group (Figure 4$)(\mathrm{p}<0.05)$.

\section{Western blot analysis}

\section{of NF- $x$ B $p 65$ and I- $x$ B protein expression}

The Western blot analysis was employed to semi-quantitatively determine protein expression levels of NF- $x \mathrm{~B}$ p65 (65 kDa), I- $\varkappa$ B (39 kDa), and $\beta$-actin (43 kDa) (Figure 5). Relative I- $x$ B level (ratios of I- $x$ B to $\beta$-actin) analyzed by densitometry was lower in the case of silica-in- duced rats, as compared with the sham group. Treatment with IFX significantly increased the I- $\varkappa \mathrm{B}$ protein level on day 7 and 14 (Figure 5b) $(\mathrm{p}<0.05)$. In contrast to the downtrend of I- $\varkappa$ B levels, relative NF- $\varkappa$ B p65 levels (ratios of NF- $\chi \mathrm{B}$ p65 to $\beta$-actin) were increased in the case of the silica rats to a larger extent than in the case of the sham animals $(\mathrm{p}<0.05)$. However, the increasing was significantly attenuated in the case of IFX-treatment rats on day 7 ( $p<0.05)$ but not on day 14 (Figure $5 d$ ).

\section{DISCUSSION}

Silicosis is associated with persistent inflammation which leads to fibroblast formation and excessive collagen deposition resulting in interstitial fibrosis [31]. In this study, histopathological analyses have revealed that a singledose intratracheal silica instillation could produce early acute alveolitis, characterized by inflammatory cells infiltration into the alveoli, accompanied by early alveolar walls thickening. Furthermore, granulomas apparently formed and extensive collagen deposition increased over time indicated progressive pulmonary inflammation and pulmonary fibrosis as compared with the sham group, closely mimicking acute silicosis injury [30]. Infliximabattenuated silica induced the early inflammation and the subsequent fibrosis, supported by a marked decrease in the distribution and severity of infiltrates, organized granulomas and collagen deposition following IFX adminis- 

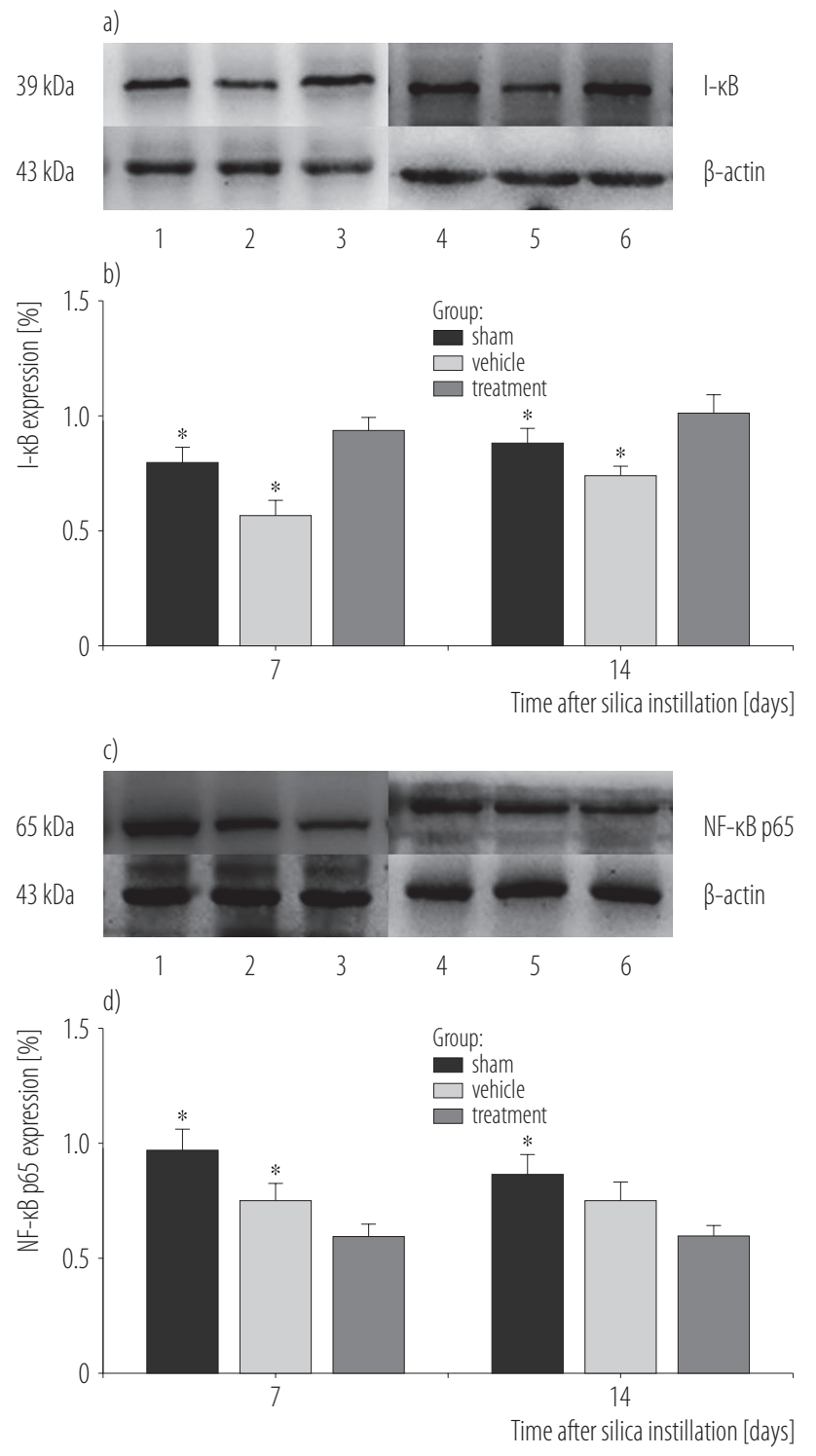

a) a representative western blot.

c) the analysis of the ratio between $\mathrm{I}-\varkappa \mathrm{B}$ and $\beta$-actin and between NF- $x \mathrm{~B}$ p 65 and $\beta$-actin by densitometry. 1 - vehicle group, day 7;2 - treatment group, day 7;3 - sham group, day $7 ; 4$ - vehicle group, day 14; 5 - treatment group, day 14 ; 6 - sham group, day 14 .

Data presented as mean \pm standard error.

$* p<0.05$, compared with sham/vehicle group (one-way analysis of variance and least significant difference test).

Groups as in Figure 1.

Fig. 5. Effect of different treatments in the rats' lung tissues on the expression of: $a$ ) and $b$ ) inhibitor protein- $x \mathrm{~B}(\mathrm{I}-\boldsymbol{x B})$, c) and d) nuclear factor- $\varkappa \mathrm{B}$ p65 (NF- $\varkappa \mathrm{B}$ p65) tration. This result is consistent with previous studies that indicated the ability of IFX to decrease collagen levels in lung diseases [23-27].

To explore the possible mechanism(s) of the protective action of IFX against silica-induced fibrosis, factors of inflammatory, nuclear transcriptional and oxidative stress were evaluated in the lung tissue.

The cytokine TNF- $\alpha$ was believed to be an upstream factor, which could initiate a cascade complex of inflammatory mediators in the early inflammatory event and develop silica-induced fibrosis. Exogenous recombinant TNF- $\alpha$ augments silicotic fibrosis and anti-TNF antibody attenuates silicosis, silicosis is absent in the case of TNF- $\alpha$ receptor knockout mice, suggesting that TNF- $\alpha$ receptor signaling is needed for the development of pulmonary inflammation and fibrosis [8-10]. In confirmation of the previous study, we observed that TNF- $\alpha$ level in serum over the time and in BALF on day 7 increased in the vehicle group to an extent greater than in the sham group, while IFX treatment significantly decreased TNF- $\alpha$ levels, which is similar to the trend of histopathological results. However, BALF TNF- $\alpha$ level on day 14 didn't show the remarkable decreasing upon IFX treatment. We analyzed the IFX administration of intraperitoneal injection which might result in the more unstable drug concentration distribution in local lung tissues, as compared with the in-the-blood system.

Nuclear factor- $x \mathrm{~B}$ has been considered a primary target to accelerate silica-induced inflammation and fibrosis in the lung [32]. Tumor necrosis factor $\alpha$ induces NF- $x$ B transactivation by a mechanism involving I- $\chi \mathrm{B}$ degradation [33]. Tumor necrosis factor-persistent stimulation may lead new I- $x$ B-NF- $x$ B complexes to enter the feedback loop, beginning with phosphorylation of I- $\varkappa \mathrm{B}$ [34]. A pharmacologic inhibitor (BAY 11-7085) of $\mathrm{I}-\varkappa \mathrm{B} \alpha$ (NF- $\varkappa \mathrm{BIA}$ ) phosphorylation, inhibiting systemically NF- $x$ B activation, significantly decreases silica-induced inflammation and fibrosis by reducing apoptosis and collagen deposition [35]. 
In the current study, silica installation induced the activation of NF- $x$ B signaling pathway, which was confirmed as followed. Firstly, by immunohistochemical staining of the lung tissue, silica exposure significantly increased the NF- $x \mathrm{~B}$ p65 level of nuclear protein distributed in nucleus and cytoplasm of alveolar macrophages and epithelial cells. Secondly, by protein band analysis of western blotting, silica exposure apparently increased I- $x \mathrm{~B}$ degradation and NF- $x \mathrm{~B}$ p65 expression. Infliximab administration considerably inhibited NF- $\chi \mathrm{B}$ signaling activation by decreasing protein level and nuclear translocation of NF- $x \mathrm{~B}$ p 65 , I- $x$ B phosphorylation as well. However, the result of NF- $x \mathrm{~B}$ p65 expression by IHC staining kept inconsistency with that by the WB analysis on day 14 . Considering the methodological difference between the 2 technologies, companied with possibly weakened NF- $x$ B signaling feedback loop over time, IHC staining result, mainly measuring combining and dissociative NF- $x$ B p65 with intracytoplasmic I- $x$ B and nucleous DNA, appeared more remarkable than that by the western blot (WB), which is measuring merely dissociative ones.

Silica-induced inflammation and oxidative stress environment contributes to lung injury. It has been demonstrated that iNOS (iNOS)-dependent formation of NO has a key role in the initiation of pulmonary inflammation and fibrosis [36]. Quartz instillation into rat lungs resulted in increasing of mRNA for iNOS in alveolar macrophages [37]. Tumor necrosis factor $\alpha$ may activate iNOS to produce NO in respiratory epithelium [17], which has been reported in alveolar macrophages and neutrophils [36,38].

The over-produced iNOS-dependent formation of NO may cause serious lung damage though the formation of peroxynitrite (reactive nitrogen species - RNS) combining with superoxide $[36,39,40]$. Furthermore, NO produces and amplifies the inflammatory response by up-regulating the key cytokine TNF- $\alpha$ during inflam- mation [22]. In our study, silica administration increased iNOS expression, which was shown by the quantitative real-time PCR analysis of iNOS mRNA expression, basically identifying with the previous conclusions. However, IFX treatment decreased INOS expression on both day 7 and 14. We have supposed that it may be one of the mechanisms, due to which IFX improves inflammation and fibrosis by decreasing transcriptional activation of oxidant-stress index iNOS.

In clinical studies, it has been shown that IFX diminishes pulmonary fibrosis via blocking TNF- $\alpha[41,42]$, and pulmonary fibrosis is not a contraindication for TNF- $\alpha$ inhibitor therapy of rheumatology [43]. Altintas et al. [27] have evaluated the preventive effect of IFX in bleomycininduced pulmonary fibrosis, eliminating the harmful effect of IFX per se on pulmonary fibrosis. However, there is no study to explain the treatment effect of IFX on silica-induced pulmonary inflammation and fibrosis.

This study has shown that IFX treatment prevents the inflammatory and fibrotic response as assessed from quantitative histopathological evaluation of silicainduced lung fibrosis model in the case of rats. In addition, it has also been found that IFX attenuates the silica-induced inflammatory by decreasing TNF- $\alpha$ level, I- $\chi \mathrm{B}$ degradation, NF- $\varkappa \mathrm{B}$ p65 expression and nuclear translocation, oxidative stress relative enzyme iNOS activities in the damaged lung tissue of rats. To the best of our knowledge, this is the first study that evaluates the treatment effect of IFX on silica-induced lung fibrosis in terms of the animal model, but it needs more indicators and data of pulmonary fibrosis to confirm. This study hopes to provide drug treatment for pneumoconiosis patients to alleviate the pain and improve the quality of life, so as to provide some help for clinical diagnosis and treatment. With the Chinese government to further strengthen the occupational precautionary measures, the occurrence of occupational diseases will be significantly reduced. 


\section{CONCLUSIONS}

In summary, IFX may improve silica-induced pulmonary inflammation by decreasing the TNF- $\alpha$, inhibiting NF- $x \mathrm{~B}$ signaling (I- $x \mathrm{~B}, \mathrm{NF}-\varkappa \mathrm{B}$ p65) as well as oxidant status (iNOS), which suggest that IFX has potential role in the treatment of silica-induced lung damage.

\section{ACKNOWLEDGMENTS}

The authors would like to acknowledge with deep appreciation and gratitude to the invaluable help of the following persons: You-xin Ji, M.D., Ph.D (North Shore University Hospital, Manhasset, NY) for this article text corrections.

\section{REFERENCES}

1. Castranova V, Vallyathan V. Silicosis and coal workers' pneumoconiosis. Environ Health Perspect. 2000;108 Suppl 4: 675-84.

2. Hamilton RF Jr, Thakur SA, Holian A. Silica binding and toxicity in alveolar macrophages. Free Radic Biol Med. 2008;44(7):1246-58, https://doi.org/10.1016/j.freeradbiomed. 2007.12.027.

3. Driscoll KE, Lindenschmidt RC, Maurer JK, Higgins JM, Ridder G. Pulmonary response to silica or titanium dioxide: Inflammatory cells, alveolarmacrophage-derived cytokines, and histopathology. Am J Respir Cell Mol Biol. 1990;2(4):381-90, https://doi.org/10.1165/ajrcmb/2.4.381.

4. American Thoracic Society. Adverse effects of crystalline silica exposure. American Thoracic Society Committee of the Scientific Assembly on Environmental and Occupational Health. Am J Respir Crit Care Med. 1997;155(2):761-8, https://doi.org/10.1164/ajrccm.155.2.9032226.

5. Cohen R, Velho V. Update on respiratory disease from coal mine and silicadust. Clin Chest Med. 2002;23(4):811-26, https://doi.org/10.1016/S0272-5231(02)00026-6.

6. Rimal B, Greenberg AK, Rom WN. Basic pathogenetic mechanisms in silicosis: Current understanding. Curr Opin Pulm Med. 2005 Mar;11(2):169-73, https://doi.org/10.1097/01.mcp. 0000152998.11335.24.
7. Miyazaki Y, Araki K, Vesin C, Garcia I, Kapanci Y, Whitsett JA, et al. Expression of a tumor necrosis factor-alpha transgene in murine lung causes lymphocytic and fibrosing alveolitis. A mouse model of progressivepulmonary fibrosis. J Clin Invest. 1995;96(1):250-9, https://doi.org/10.1172/ JCI118029.

8. Piguet PF, Collart MA, Grau GE, Sappino AP, Vassalli P. Requirement of tumour necrosis factor for development of silica-induced pulmonary fibrosis. Nature. 1990;344(6263): 245-7, https://doi.org/10.1038/344245a0.

9. Gossart S, Cambon C, Orfila C, Séguélas MH, Lepert JC, Rami J, et al. Reactive oxygen intermediates as regulators of TNF-alpha production in ratlung inflammation induced by silica. J Immunol. 1996;156(4):1540-8.

10. Ortiz LA, Lasky J, Lungarella G, Cavarra E, Martorana P, Banks WA, et al. Upregulation of the p75 but not the p55TNF- $\alpha$ receptor mRNA after silica and bleomycin exposure and protection from lung injury in double receptor knockout mice. Am J Respir Cell Mol Biol. 1999;20(4): 825-33, https://doi.org/10.1165/ajrcmb.20.4.3193.

11. Baeuerle PA, Baltimore D. NF-kappa B: 10 years after. Cell. 1996;87(1):13-20, https://doi.org/10.1016/S0092-8674 (00)81318-5.

12. Hoffmann A, Levchenko A, Scott ML, Baltimore D. The IkappaB-NF- $x$ B signaling module: Temporal control and selective gene activation. Science. 2002;298(5596):1241-5, https://doi.org/10.1126/science.1071914.

13. Perkins ND. Integrating cell-signaling pathways with NF- $\varkappa B$ and IKK function. Nat Rev Mol Cell Biol. 2007;8(1): 49-62, https://doi.org/10.1038/nrm2083.

14. Hubbard AK, Timblin CR, Shukla A, Rincón M, Mossman BT. Activation of NF- $\chi \mathrm{B}$-dependent gene expression by silica in lungs of luciferase reporter mice. Am J Physiol Lung Cell Mol Physiol. 2002;282(5):L968-75, https://doi. org/10.1152/ajplung.00327.2001

15. Porter DW, Ye J, Ma J, Barger M, Robinson VA, Ramsey $\mathrm{D}$, et al. Time course of pulmonary response of rats to inhalation of crystalline silica: NF-kappa B activation, 
inflammation, cytokine production, and damage. Inhal Toxicol. 2002;14(4):349-67, https://doi.org/10.1080/0895837 0252870998 .

16. Ortiz LA, Lasky J, Gozal E, Ruiz V, Lungarella G, Cavarra E, et al. Tumor necrosis factor receptor deficiency alters matrix metalloproteinase 13/tissue inhibitor of metalloproteinase 1 expression in murine silicosis. Am J Respir Crit Care Med. 2001;163(1):244-52, https://doi.org/10.1164/ajr ccm.163.1.2002123.

17. Torreilles J. Nitric oxide: One of the more conserved and widespread signaling molecules. Front Biosci. 2001;6: D1161-72, https://doi.org/10.2741/torreill.

18. Zeidler P, Hubbs A, Battelli L, Castranova V. Role of inducible nitric oxide synthase-derived nitric oxide in silicainduced pulmonary inflammation and fibrosis. J Toxicol Environ Health A. 2004;67(13):1001-26, https:/doi. org/10.1080/15287390490447296.

19. Zinetti M, Fantuzzi G, Delgado R, Di Santo E, Ghezzi P, Fratelli M. Endogenous nitric oxide production by human monocytic cells regulates LPS-induced TNF production. Eur Cytokine Netw. 1995 Jan-Feb;6(1):45-8.

20. Sartani G, Silver PB, Rizzo LV, Chan CC, Wiggert B, Mastorakos G, et al. Anti-tumor necrosis factor alpha therapy suppresses the induction of experimental autoimmune uveoretinitis in mice by inhibiting antigen priming. Invest Ophthalmol Vis Sci. 1996;37(11):2211-8.

21. Scallon BJ, Moore MA, Trinh H, Knight DM, Ghrayeb J. Chimeric anti-TNF- $\alpha$ monoclonal antibody cA2 binds recombinant transmembrane TNF- $\alpha$ and activates immune effector functions. Cytokine. 1995;7(3):251-9, https://doi. org/10.1006/cyto.1995.0029

22. Knight DM, Trinh H, Le J, Siegel S, Shealy D, Mc Donough $\mathrm{M}$, et al. Construction and initial characterization of a mouse-human chimeric anti-TNF antibody. Mol Immunol. 1993;30(16):1443-53, https://doi.org/10.1016/0161-5890 (93)90106-L.

23. Cai Y, Cao YX, Lu SM, Xu CB, Cardell LO. Infliximab alleviates inflammation and ex vivo airway hyperreactivity in asthmatic E3 rats. Int Immunol. 2011;23(7):443-51, https:// doi.org/10.1093/intimm/dxr032.

24. Güzel A, Günaydin M, Güzel A, Alaçam H, Murat N, Gacar A, et al. Infliximab attenuates activated charcoal and polyethylene glycol aspiration-induced lung injury in rats. Exp Lung Res. 2012;38(3):147-56, https://doi.org/10.3109/ 01902148.2012.659836.

25. Zhang XY, Zhang C, Sun QY, Li D, Luo RR, Wan ZF, et al. Infliximab protects against pulmonary emphysema in smoking rats. Chin Med J (Engl). 2011;124(16):2502-6.

26. Guzel A, Kanter M, Guzel A, Pergel A, Erboga M. Antiinflammatory and antioxidant effects of infliximab on acute lung injury in a rat model of intestinal ischemia/reperfusion. J Mol Histol. 2012;43(3):361-9, https://doi.org/10.1007/s10 735-012-9396-0.

27. Altintas N, Erboga M, Aktas C, Bilir B, Aydin M, Sengul A, et al. Protective effect of infliximab, a tumor necrosis factoralfa inhibitor, on bleomycin-induced lung fibrosis in rats. Inflammation. 2016;39(1):65-78, https://doi.org/10.1007/ s10753-015-0224-z.

28. Zhao F-F, Wang S-X, Zeng J-W, He-Bing, Tu Z-G. [Utilizing SELDI-TOF-MS to screen serum biomarkers and establish serum protein fingerprints for the classification and decision tree of silicoticrats]. Acta Acad Med CPAPF. 2007;3:209215,343. Chinese.

29. Lacher SE, Johnson C, Jessop F, Holian A, Migliaccio CT. Murine pulmonary inflammation model: A comparative study of anesthesia and instillation methods. Inhal Toxicol. 2010;22(1):77-83, https://doi.org/10.3109/08958370902929969.

30. Triantafillidis JK, Papalois AE, Parasi A, Anagnostakis E, Burnazos S, Gikas A, et al. Favorable response to subcutaneous administration of infliximab in rats with experimental colitis. World J Gastroenterol. 2005;11(43):6843-7, https:// doi.org/10.3748/wjg.v11.i43.6843.

31. Thakur SA, Beamer CA, Migliaccio CT, Holian A. Critical role of MARCO in crystalline silica-induced pulmonary inflammation. Toxicol Sci. 2009;108(2):462-71, https://doi. org/10.1093/toxsci/kfp011. 
32. Hubbard AK, Timblin CR, Shukla A, Rincón M, Mossman BT. Activation of NF- $x$ B-dependent gene expression by silica in lungs of luciferase reporter mice. Am J Physiol Lung Cell Mol Physiol. 2002;282(5):L968-75, https://doi. org/10.1152/ajplung.00327.2001.

33. Cheshire JL, Baldwin AS Jr. Synergistic activation of NF-kappaB by tumor necrosis factor alpha and gamma interferon via enhanced I kappaB alpha degradation and denovo IkappaBbeta degradation. MolCellBiol.1997;17(11): 6746-54, https://doi.org/10.1128/MCB.17.11.6746.

34. Cheong R, Hoffmann A, Levchenko A. Understanding NF- $x$ B signaling via mathematical modeling. Mol Syst Biol. 2008;4:192, https://doi.org/10.1038/msb.2008.30.

35. Di Giuseppe M, Gambelli F, Hoyle GW, Lungarella G, Studer SM, Richards T, et al. Systemic inhibition of NF- $x$ B activation protects from silicosis. PLoS One. 2009;4(5):e5689, https://doi.org/10.1371/journal.pone.0005689.

36. Zeidler P, Hubbs A, Battelli L, Castranova V. Role of inducible nitric oxidesynthase-derived nitric oxide in silicainduced pulmonary inflammation and fibrosis. $\mathrm{J}$ Toxicol Environ Health A. 2004;67(13):1001-26, https://doi. org/10.1080/15287390490447296.

37. Castranova V, Kang JH, Moore MD, Pailes WH, Frazer DG, Schwegler-Berry D. Inhibition of stimulant-induced activation of phagocytic cells with tetrandrine. J Leukoc Biol. 1991;50(4):412-22.

38. Castranova V, Huffman LJ, Judy DJ, Bylander JE, Lapp LN, Weber SL, et al. Enhancement of nitric oxide production by pulmonary cells following silica exposure. Environ Health Perspect. 1998;106 Suppl 5:1165-9, https://doi.org/10.1289/ ehp.98106s51165.

39. Beckman JS, Beckman TW, Chen J, Marshall PA, Freeman BA. Apparent hydroxylradical production by peroxynitrite: Implications for endothelial injury from nitric oxide and superoxide. Proc Natl Acad Sci U S A. 1990;87(4):16204, https://doi.org/10.1073/pnas.87.4.1620.

40. Koppenol WH, Moreno JJ, Pryor WA, Ischiropoulos H, Beckman JS. Peroxynitrite, a cloaked oxidant formed by nitric oxide and superoxide. Chem Res Toxicol. 1992;5(6): 834-42, https://doi.org/10.1021/tx00030a017.

41. Bargagli E, Galeazzi M, Rottoli P. Infliximab treatment in a patient with rheumatoid arthritis and pulmonary fibrosis. Eur Respir J. 2004;24(4):708, https://doi.org/10.1183/090319 36.04.00076904.

42. Bargagli E, Galeazzi M, Bellisai F, Volterrani L, Rottoli P. Infliximab treatment in a patient with systemic sclerosis associated with lung fibrosis and pulmonary hypertension. Respiration. 2008;75(3):346-9, https://doi.org/10.1159/000090248. 43. Saag KG, Teng GG, Patkar NM, Anuntiyo J, Finney C, Curtis JR, et al. American College of Rheumatology 2008 recommendations for the use of nonbiologic and biologic disease-modifying antirheumatic drugs in rheumatoid arthritis. Arthritis Rheum. 2008;59(6):762-84, https://doi. org/10.1002/art.23721.

This work is available in Open Access model and licensed under a Creative Commons Attribution-NonCommercial 3.0 Poland License - http://creativecommons.org/ licenses/by-nc/3.0/pl/deed.en. 